\title{
Research Article \\ Electrical Properties of Nanoscale ZnS Thin Film Transistor
}

\author{
Teresa Oh \\ Semiconductor Engineering, Cheongju University, 298 Daesung-ro Chungwon-ku, Cheongju 360-764, Republic of Korea \\ Correspondence should be addressed to Teresa Oh; teresa@cju.ac.kr
}

Received 3 March 2015; Revised 28 May 2015; Accepted 2 June 2015

Academic Editor: Edward A. Payzant

Copyright (C) 2015 Teresa Oh. This is an open access article distributed under the Creative Commons Attribution License, which permits unrestricted use, distribution, and reproduction in any medium, provided the original work is properly cited.

\begin{abstract}
To understand the contact mechanism from electrical properties of the ZnS TFTs, ZnS was fabricated on SiOC as a gate insulator on a Si substrate. Ohmic contact without a potential barrier increased the leakage current, but Schottky contact decreased the leakage current because of a Schottky barrier (SB). The ZnS TFTs prepared on SiOC with a Schottky contact improved the stability with respect to the reduction of drain voltages. The structural matching between $\mathrm{ZnS}$ and SiOC increased the height of SB such as $\mathrm{ZnS}$ annealed at $200^{\circ} \mathrm{C}$, which made $\mathrm{ZnS}$ become an amorphous structure. ZnS/SiOC films with a low SB increased the capacitance and leakage current. The crystallinity orientation of $\mathrm{ZnS}$ localized defect states and the drift current owing to the impurity charge carriers caused the leakage current through low SB near zero voltages. But the increment of diffusion currents in a depletion layer increased the SB and then decreased the leakage current. So the electrical properties of devices were improved by a tunneling effect of diffusion currents.
\end{abstract}

\section{Introduction}

Thin films of wide band gap II-VI compounds, such as $\mathrm{CdS}$, CdSe, and $\mathrm{ZnS}$, have received considerable attention as photoelectronic materials. ZnS was used in a buffer layer for the fabrication of solar cells. Its advantages include large energy band gap, nontoxic environmental materials, and superior optical properties that make $\mathrm{ZnS}$ suitable for nanoscale devices $[1,2]$. However, the undesirable cross talk of source/drain regions and the power consumption also increase with decreasing feature size. The root cause can be attributed to poor electrostatics between the gate and the channel. Thus the detail contact mechanism in nanosize materials is explored and there is a substantial need to find new semiconductors. The thin film transistors with channel materials such as ZnS, IGZO, and AZO were usually showed as the unipolar transfer characteristics [3-8], but it was reported that $\mathrm{ZnO}$ thin film transistor that used $\mathrm{SiOC}$ as a gate insulator had bidirectional ambipolar properties. SiOC became low dielectric constant with lowering the polarity, which helps to have good chemical and physical properties for high electrical quality [9-15]. Some factors which include the interactions between $\mathrm{ZnO}$ and SiOC phases and the strong adsorption to the substrate at the $\mathrm{ZnO} / \mathrm{SiOC}$ surface are responsible for the improvement of performance [16-18].
$\mathrm{SiO}_{2}$ as a gate insulator was usually used to develop a thin film transistor device with new channel materials, and most TFTs had n-type characteristics [19-23].

In this work, the $\mathrm{ZnS}$ thin film transistor with a gate insulator SiOC was fabricated to research the Ohmic and Schottky contacts depending on annealing temperatures. In order to understand the role of conduction mechanism on the thin film transistor with $\mathrm{ZnS}$ channel, the capacitance, leakage current, $I_{\mathrm{DS}}-V_{\mathrm{DS}}$, and $I_{\mathrm{DS}}-V_{\mathrm{GS}}$ were analyzed for the correlation between Schottky contact and the transfer curves of transistors. The relationship between the depletion layer and electric potentials was also studied with increasing annealing temperatures.

\section{Experimental Procedure}

To obtain electrical characteristics and contacts of TFTs, the $\mathrm{ZnS} / \mathrm{SiOC}$ TFTs were fabricated. SiOC as a gate insulator was prepared by the RF sputtering system using the target of $\mathrm{SiOC}$, which was prepared on $\mathrm{p}$-type Si substrates at room temperature and RF power of $250 \mathrm{~W}$ for 20 minutes. ZnS was also grown on $\mathrm{SiOC} / \mathrm{Si}$ by the RF sputtering system with $70 \mathrm{~W}$ for 10 minutes. $\mathrm{ZnS} / \mathrm{SiOC}$ films were annealed at 100 , 200 , and $300^{\circ} \mathrm{C}$ to observe the $\mathrm{Ohmic} / \mathrm{Sch}$ httky contacts. The target to substrate distance was kept at $100 \mathrm{~mm}$ and the base 


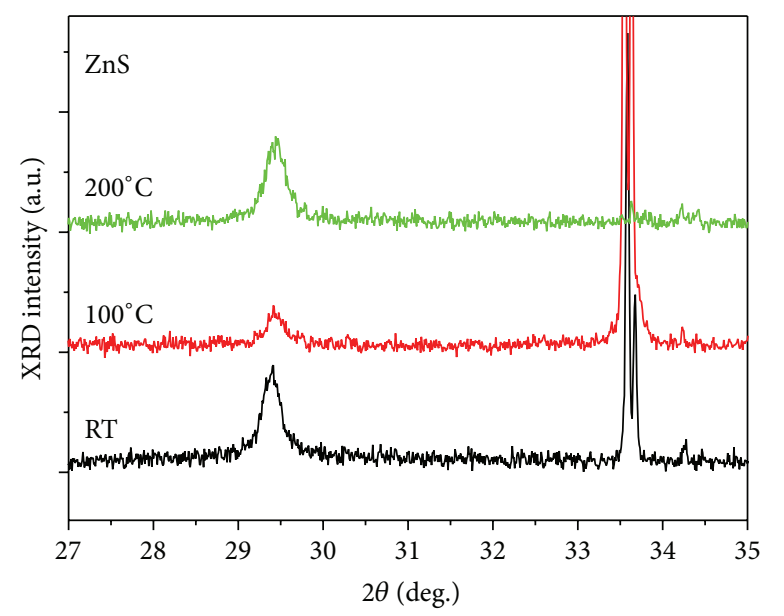

(a)

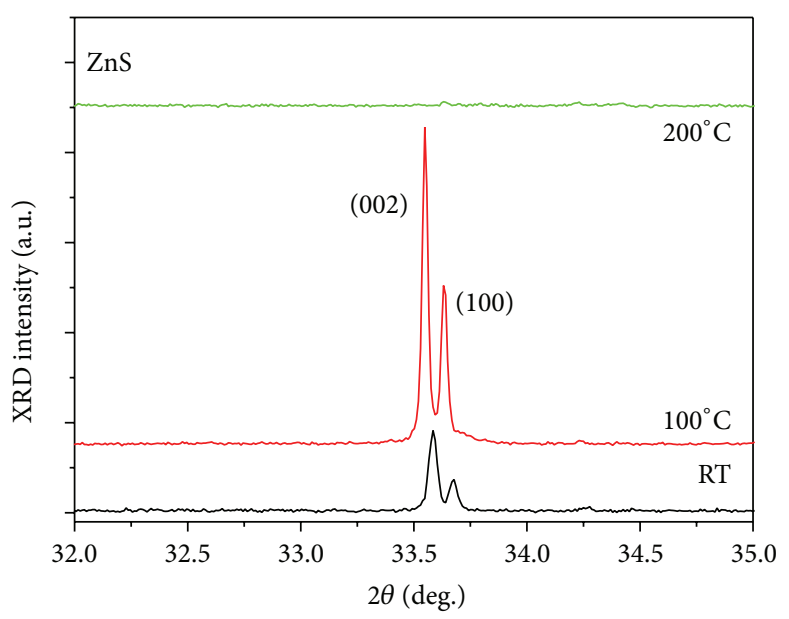

(b)

FIGURE 1: XRD patterns of $\mathrm{ZnS}$ with annealing temperatures near 2 theta of (a) $29.3^{\circ}$ and (b) $33.6^{\circ}$.

pressure was $4.5 \times 10^{-5} \mathrm{~Pa}$ and the working pressure of the chamber with oxygen gas was $1.2 \sim 1.4 \times 10^{-3}$ Torr. The oxygen (99.9999\%) was controlled by mass flow controller (MFC) for $20 \mathrm{~min}$. For the analysis of electric properties, the aluminum was evaporated using the mask pattern on the surface of the specimen, where the sputter-deposited aluminum with an area of $(0.1 / 2)^{2} \times \pi \mathrm{cm}$ was used on the top electrode. Electrical leakage currents for the films were measured by the semiconductor parameter analyzer (HP 4140B) at $1 \mathrm{MHz}$ using MIS (metal/insulator/Si, Al/SiOC films/p-Si) structure. Capacitance was researched by the precision LCR meter (4284A), and the transfer characteristics of TFTs were done by the HP4155A. To research the characteristics of $\mathrm{ZnS}$ and dependence on temperatures and insulator SiOC, the $\mathrm{ZnS}$ and $\mathrm{ZnS} / \mathrm{SiOC}$, which were prepared with various annealing temperatures, were analyzed by PL and XRD patterns.

\section{Results and Discussions}

The depletion layer, which is related to a height of Schottky barrier (SB), is an important factor to define Schottky and
Ohmic contacts [24-27]. In the depletion layer in semiconductors, diffusion currents enhance and drift currents cutoff; therefore, the depletion layer at a junction makes the Schottky barrier in semiconductor devices. To understand contact mechanism, the temperature dependence at an interface of a thin film fabricated on $\mathrm{Si}$ and an interface between SiOC and $\mathrm{ZnS}$ was researched, and the electrical properties of $\mathrm{ZnS}$ TFTs were researched by the HP4155A.

The crystalline orientation of the $\mathrm{ZnS}$ was determined at about $29.3^{\circ}$ and $33.6^{\circ}$ using XRD patterns with annealing temperatures as shown in Figure 1. The XRD patterns near $29.3^{\circ}$ did not shift with increasing the temperatures, but the intensity of peaks near $33.6^{\circ}$ increased at $\mathrm{ZnS}$ annealed at $100^{\circ} \mathrm{C}$. Moreover, the peak near $33.6^{\circ}$ of $\mathrm{ZnS}$ annealed at $200^{\circ} \mathrm{C}$ disappeared and it means that it became an amorphous structure. Therefore, the crystalline orientation of the $\mathrm{ZnS}$, which has a wurtzite structure to match with a substrate, was the highest at $100^{\circ} \mathrm{C}$ annealing.

Figure 2 compares the optical transmission spectra between $\mathrm{ZnS}$, SiOC, and $\mathrm{ZnS} / \mathrm{SiOC}$ grown on $\mathrm{Si}$ wafer substrate measured at room temperature by UV-visible 


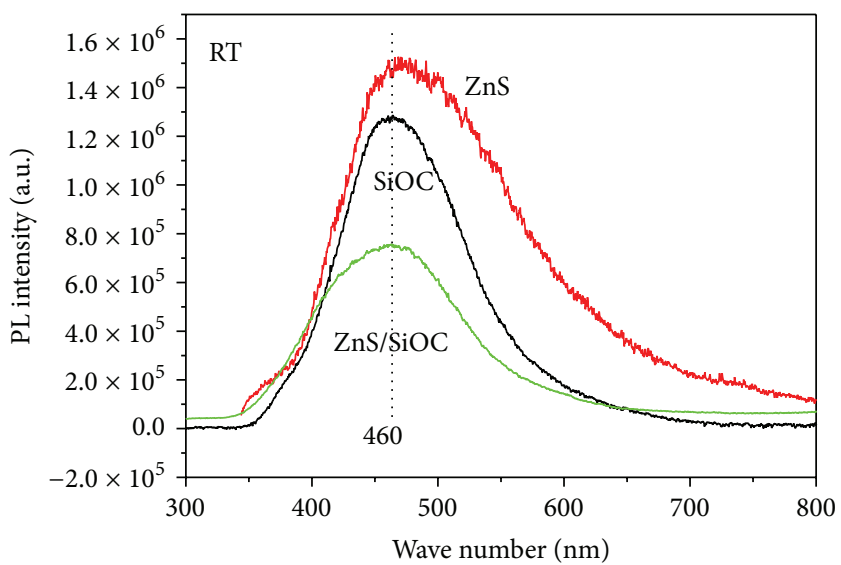

Figure 2: Comparison of PL spectra between ZnS, SiOC, and ZnS/SiOC.
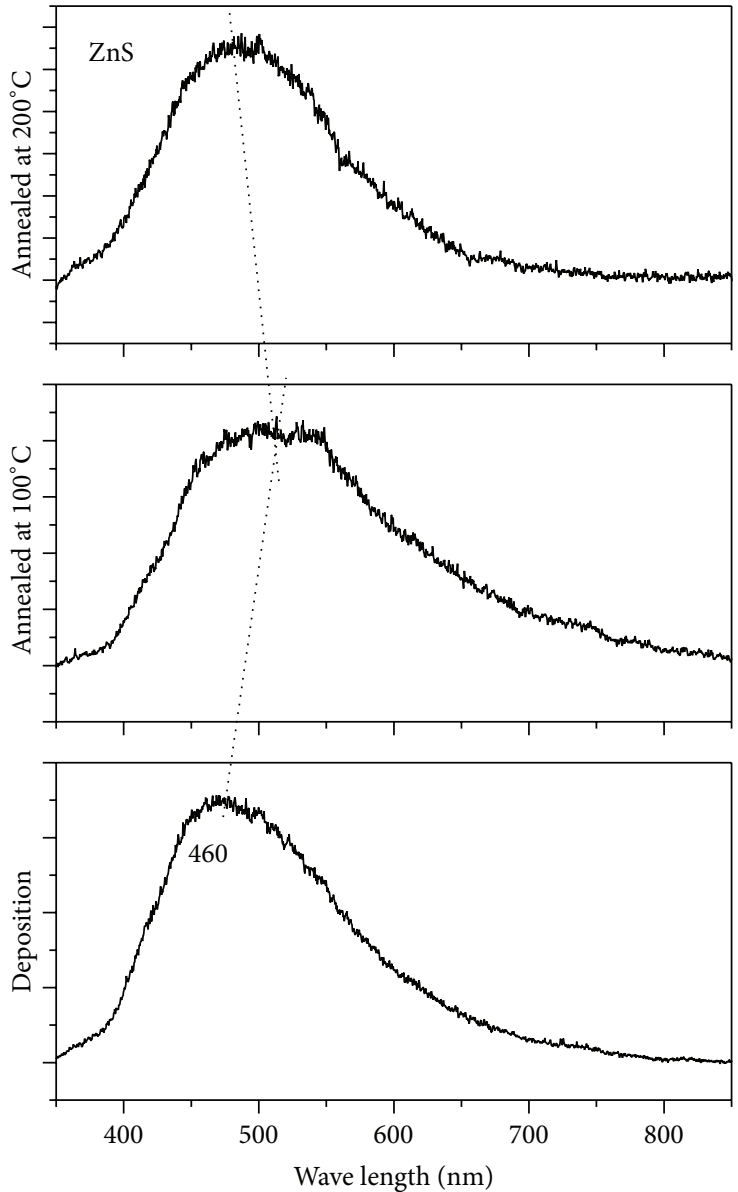

(a)
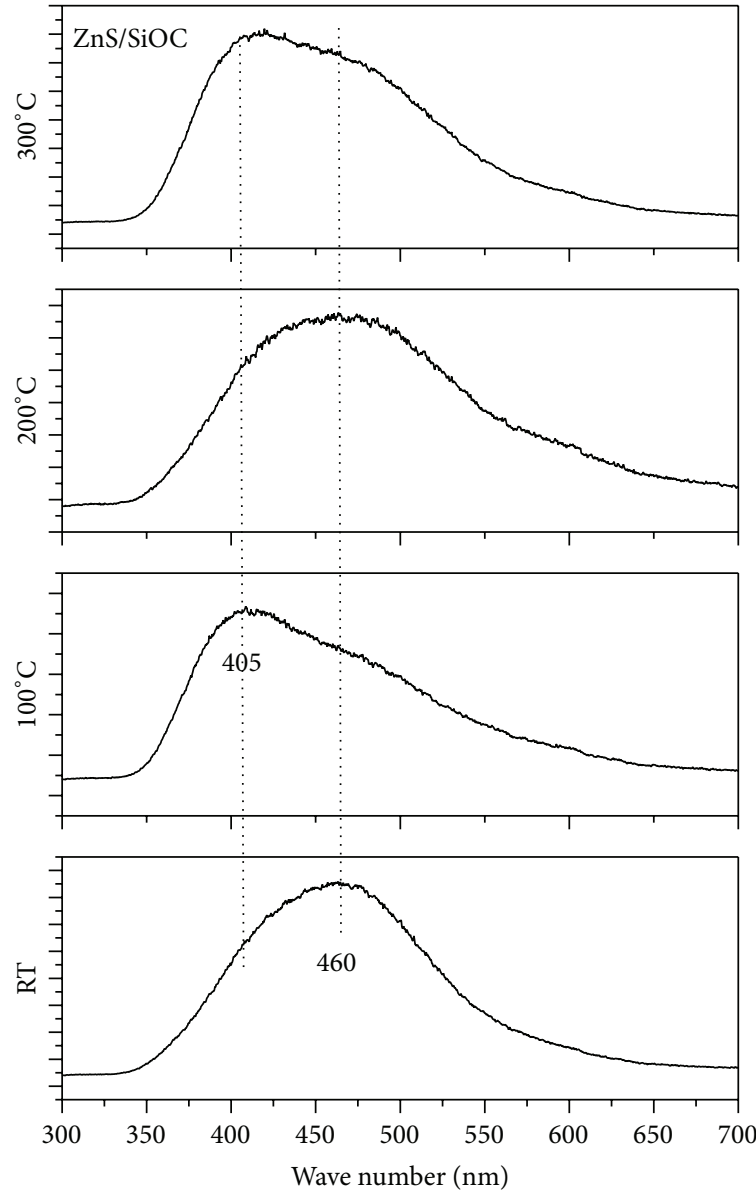

(b)

FIGURE 3: PL spectra with annealing temperatures, (a) $\mathrm{ZnS}$ and (b) $\mathrm{ZnS} / \mathrm{SiOC}$.

spectrophotometer. All of the samples showed the broad PL spectra of $350 \mathrm{~nm} \sim 800 \mathrm{~nm}$ with a main peak of $460 \mathrm{~nm}$, and the full width half maximum (FWHM) of PL of SiOC and $\mathrm{ZnS} / \mathrm{SiOC}$ was lower than that of $\mathrm{ZnS}$. The intense PL emission peak confirms the good optical property of $\mathrm{ZnS} / \mathrm{SiOC}$, so this indicates that the optical characteristic of
ZnS was improved by using SiOC due to the low surface energy and the decrease of a contact resistance at an interface between $\mathrm{ZnS}$ and SiOC $[9,10]$.

Figure 3 is PL spectra of $\mathrm{ZnS}$ and $\mathrm{ZnS} / \mathrm{SiOC}$ with annealing temperatures. The PL spectra of $\mathrm{ZnS}$ were similar formations with increasing the annealing temperature as seen 


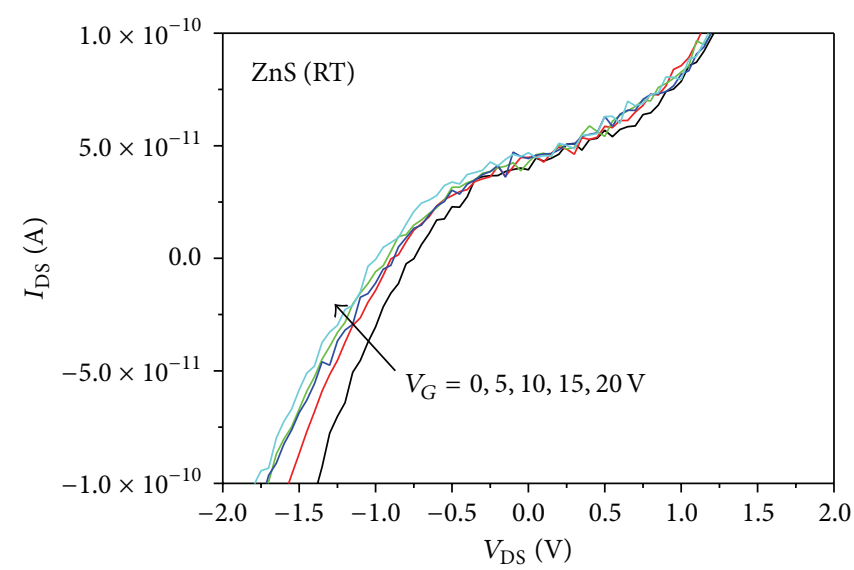

(a)

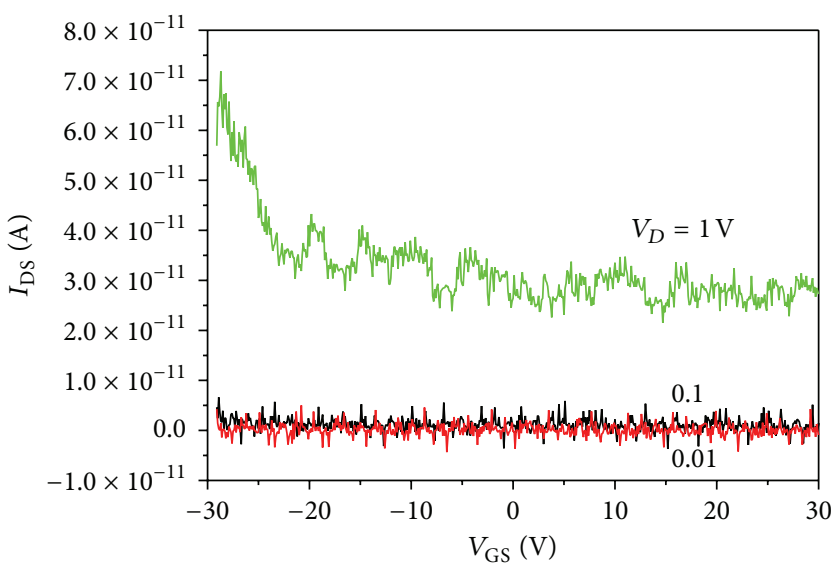

(b)

FIGURE 4: Electrical properties of ZnS TFT on SiOC/Si substrate, (a) $I_{\mathrm{DS}}-V_{\mathrm{DS}}$ curves and (b) transfer characteristics of $I_{\mathrm{DS}}-V_{\mathrm{GS}}$.

in Figure 3(a). However, those of $\mathrm{ZnS} / \mathrm{SiOC}$ were various features in accordance with the annealing temperatures, and the PL peak of $\mathrm{ZnS} / \mathrm{SiOC}$ annealed at $100^{\circ} \mathrm{C}$ moved to low wave number from $460 \mathrm{~nm}$ to $405 \mathrm{~nm}$. This result agreed with the crystalline orientation of the $\mathrm{ZnS}$ annealed at $100^{\circ} \mathrm{C}$ as previously mentioned in Figure 1(b). In particular, the strong and intrinsic PL emission peak of $\mathrm{ZnS}$ could be obtained on SiOC after annealing at $100^{\circ} \mathrm{C}$. The high level properties of oxide semiconductors which used SiOCs were reported in the author's previous paper [28]. To analyze the relationship between the crystallinity and electrical characteristics of $\mathrm{ZnS} / \mathrm{SiOC}$, the transfer characteristics of $\mathrm{ZnS} / \mathrm{SiOC}$ TFTs were measured with various drain voltages from $10 \mathrm{~V}$ to $0.001 \mathrm{~V}$. The $I_{\mathrm{DS}}-V_{\mathrm{DS}}$ was also researched to define the contact mechanism of TFTs.

Figure 4 shows the electrical $I_{\mathrm{DS}}-V_{\mathrm{DS}}$ and $I_{\mathrm{DS}}-V_{\mathrm{GS}}$ characteristics of $\mathrm{ZnS}$ TFTs with $\mathrm{SiOC}$ as a gate insulator prepared on $\mathrm{Si}$ at room temperatures. $I_{\mathrm{DS}}-V_{\mathrm{DS}}$ curves shifted to left side with increasing the gate bias voltages but $I_{\mathrm{DS}}-V_{\mathrm{GS}}$ curves could not be obtained in spite of decreasing the drain bias voltages. Because the depletion layer at an interface between $\mathrm{ZnS}$ and $\mathrm{SiOC}$ was incompletely formed, to make a depletion layer at an interface between $\mathrm{ZnS}$ and SiOC by the electron-hole recombination, $\mathrm{ZnS} / \mathrm{SiOC}$ films were annealed at 100,200 , and $300^{\circ} \mathrm{C}$.

Figure 5 is $I_{\mathrm{DS}}-V_{\mathrm{GS}}$ transfer characteristics of annealed ZnS TFTs and logarithm of $I_{\mathrm{DS}}-V_{\mathrm{GS}}$ transfer characteristics. All of the samples showed the ambipolar characteristics with decreasing the drain bias voltages. $\mathrm{ZnS} / \mathrm{SiOC}$ films annealed at $100^{\circ} \mathrm{C}$ could not obtain the $I_{\mathrm{DS}}-V_{\mathrm{GS}}$ over $V_{D}=1 \mathrm{~V}$, although $\mathrm{ZnS} / \mathrm{SiOC}$ films annealed at 200 and $300^{\circ} \mathrm{C}$ did not observe the $I_{\mathrm{DS}}-V_{\mathrm{GS}}$ curves over $V_{D}=5 \mathrm{~V}$.

To understand the correlation between diffusion currents and $I_{\mathrm{DS}}-V_{\mathrm{GS}}$ curves, the $I_{\mathrm{DS}}-V_{\mathrm{GS}}$ transfer characteristics in the range of $-5 \mathrm{~V}<V_{\mathrm{GS}}<5 \mathrm{~V}$ of annealed $\mathrm{ZnS}$ TFTs was researched as shown in Figure 6. The log plotted $I_{\mathrm{DS}}-V_{\mathrm{GS}}$ curves of $\mathrm{ZnS}$ TFT annealed at 100 and $300^{\circ} \mathrm{C}$ were shown as the distortion. This means that the depletion layer annealed at $200^{\circ} \mathrm{C}$ at an interface between $\mathrm{ZnS}$ and $\mathrm{SiOC}$ was superior compared to others.

Figure 7 displayed the $I_{\mathrm{DS}}-V_{\mathrm{DS}}$ curves of annealed $\mathrm{ZnS}$ TFTs. The $I_{\mathrm{DS}}-V_{\mathrm{GS}}$ curves of ZnS TFT annealed at 100 and 


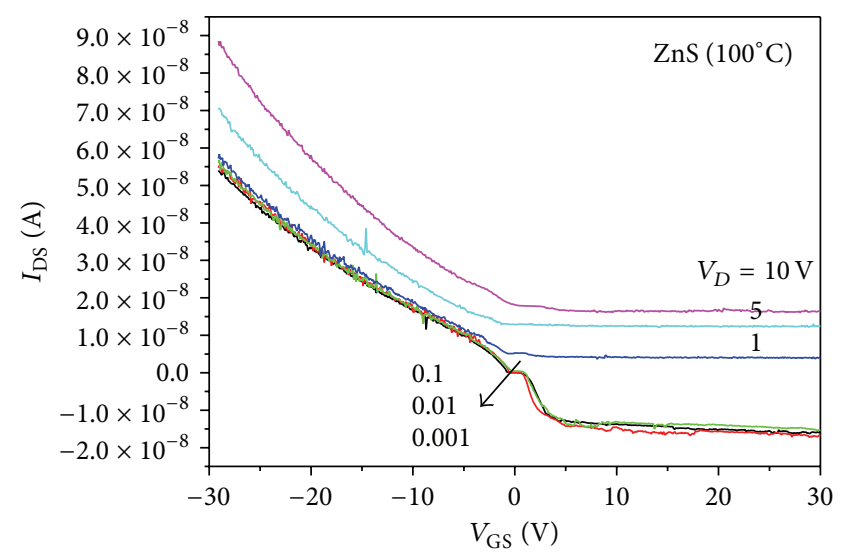

(a)

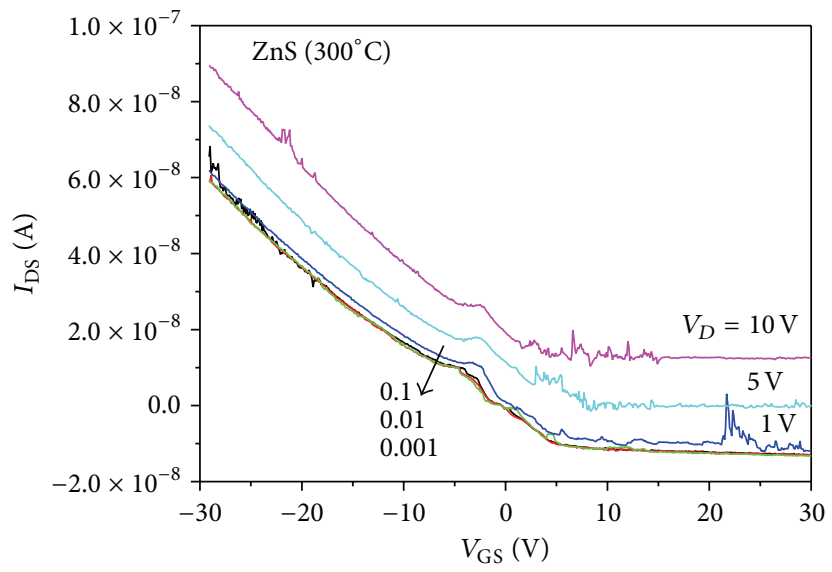

(c)

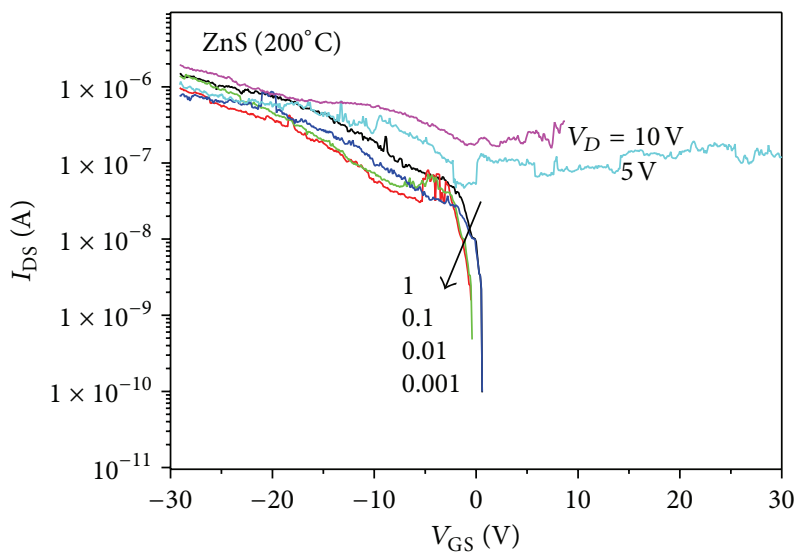

(e)

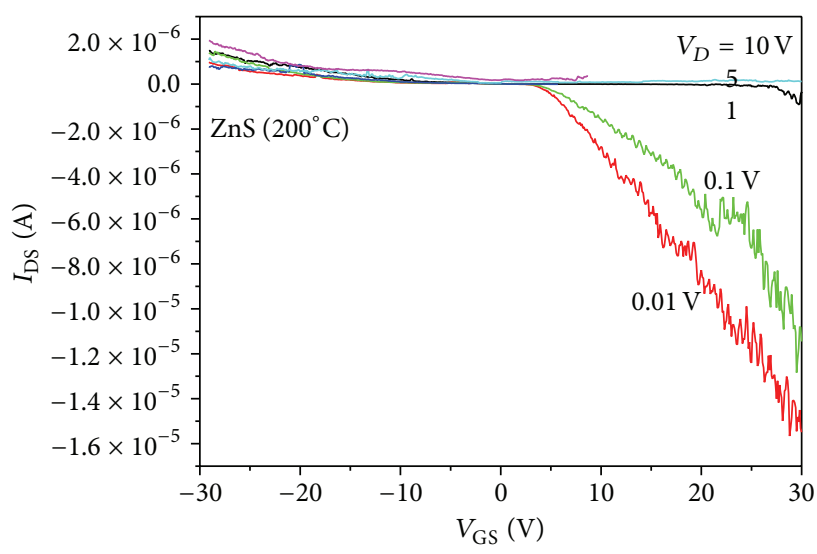

(b)

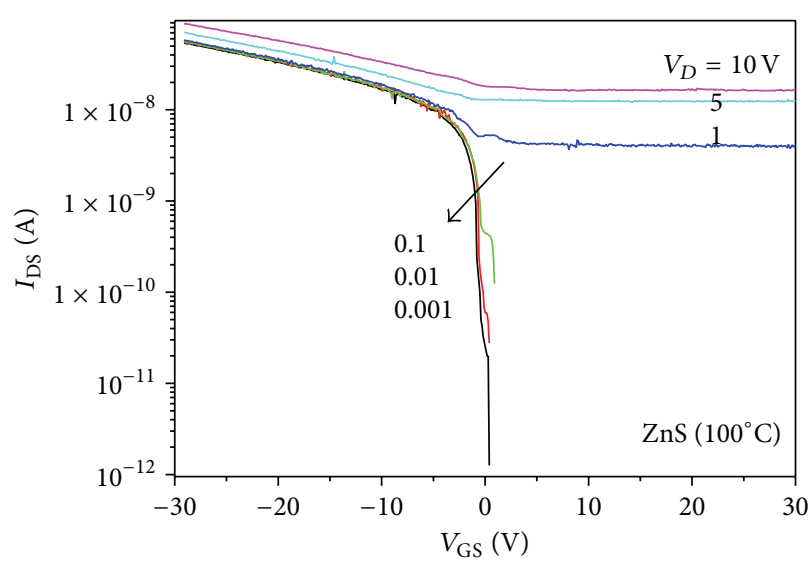

(d)

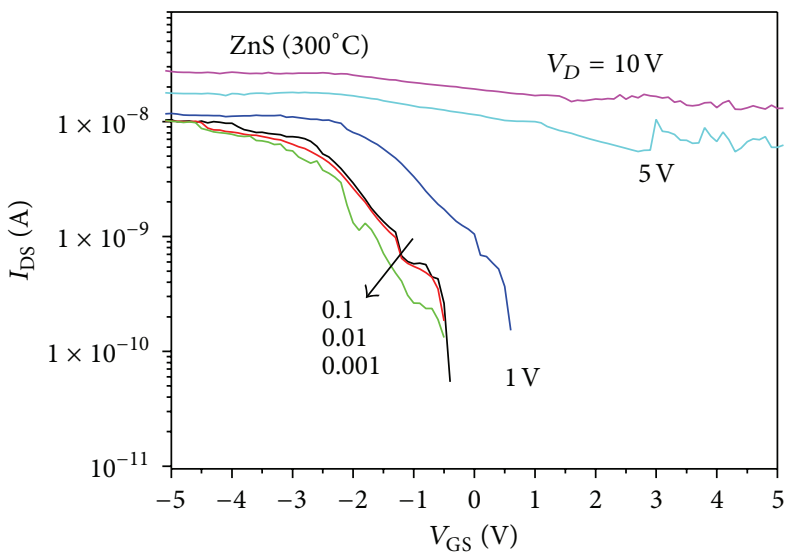

(f)

Figure 5: $I_{\mathrm{DS}}-V_{\mathrm{GS}}$ transfer characteristics of ZnS TFTs annealed at (a) $100^{\circ} \mathrm{C}$, (b) $200^{\circ} \mathrm{C}$, and (c) $300^{\circ} \mathrm{C}$; $\log$ plot of ZnS TFT annealed at (d) $100^{\circ} \mathrm{C}$, (e) $200^{\circ} \mathrm{C}$, and (f) $300^{\circ} \mathrm{C}$.

$300^{\circ} \mathrm{C}$ were similar to change right shift with increasing the gate bias voltages, but that annealed at $200^{\circ} \mathrm{C}$ was a different formation compared with other annealed films.

Figure 8 is the electrical properties of $\mathrm{ZnS} / \mathrm{SiOC} / \mathrm{Si}$ and capacitance. The leakage current of $\mathrm{ZnS} / \mathrm{SiOC} / \mathrm{Si}$ annealed at $200^{\circ} \mathrm{C}$ was the lowest and the capacitance of $\mathrm{ZnS} / \mathrm{SiOC} / \mathrm{Si}$ annealed at $200^{\circ} \mathrm{C}$ was also the lowest. The charge carriers for drift currents increased a capacitance and then decreased the SB. In the leakage current in the region of $\sim-10^{-4} \mathrm{~A}<$ current $<\sim+10^{-4} \mathrm{~A}$, most samples without a sample annealed at $200^{\circ} \mathrm{C}$ with a high Schottky barrier increased the leakage currents as shown in Figure 8(b). 


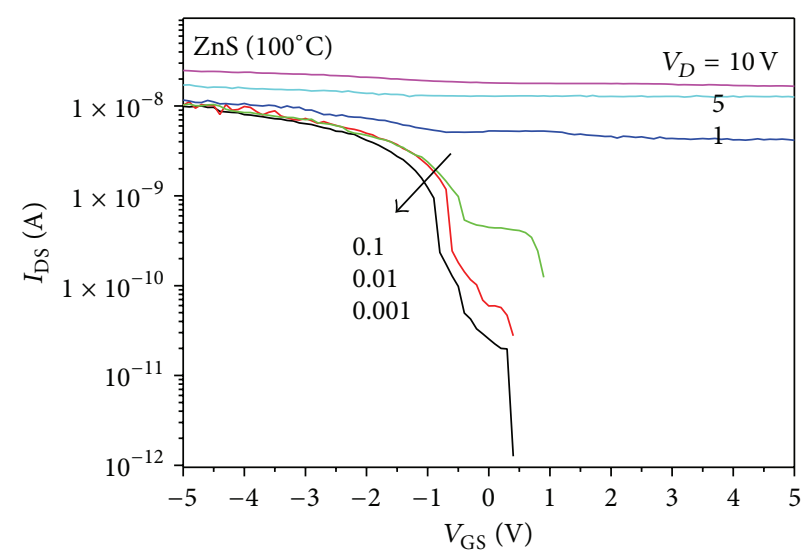

(a)

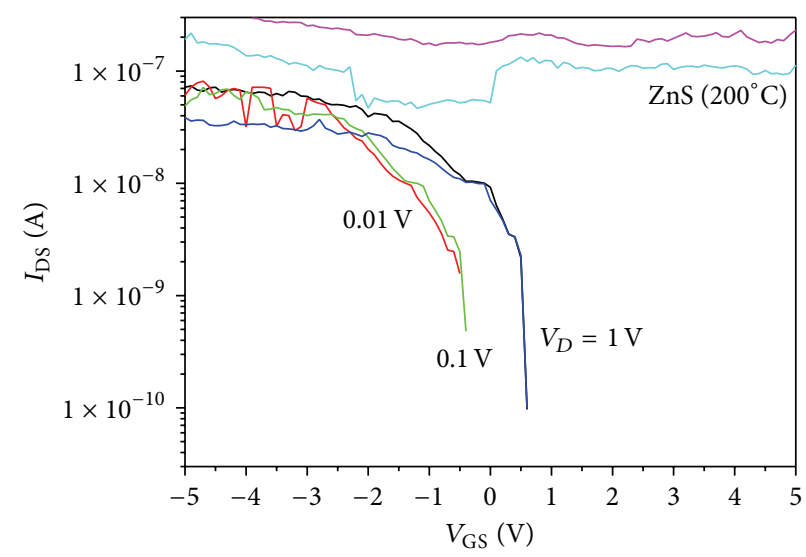

(b)

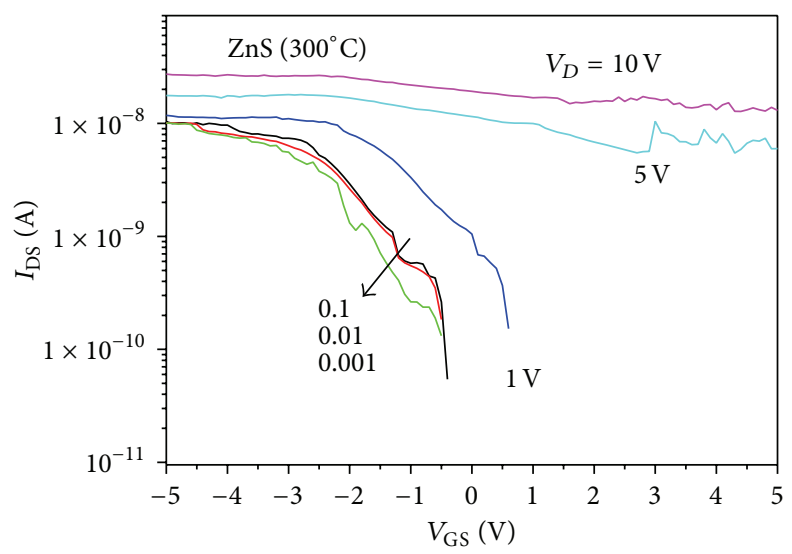

(c)

Figure 6: Log plotted $I_{\mathrm{DS}}-V_{\mathrm{GS}}$ curves of ZnS TFTs annealed at (a) $100^{\circ} \mathrm{C}$, (b) $200^{\circ} \mathrm{C}$, and (c) $300^{\circ} \mathrm{C}$.

Figure 9 was current-voltage properties in a range of $-3 \mathrm{~V}<V<3 \mathrm{~V}$, and Figure 9(b) observed the $\mathrm{ZnS} / \mathrm{SiOC} / \mathrm{Si}$ annealed at $200^{\circ} \mathrm{C}$ with Schottky contact between $\mathrm{ZnS}$ and SiOC. The growth of $\mathrm{ZnO}$ prepared on SiOC was closely related to the contact mechanism. The qualifying of $\mathrm{ZnO} / \mathrm{SiOC}$ TFTs depended on a height of SB according to the annealing temperatures. The contact mechanism was defined by leakage currents of thin films with MIS structure. In particular, the low leakage current caused high Schottky barrier and enhanced the performance about a stability of transistors as shown in Figure 6(b) compared with TFTs, which has low SB and high leakage current. This result depicts that the qualifying of Schottky contact needs high SB and low leakage currents to attend with good TFT performance. 


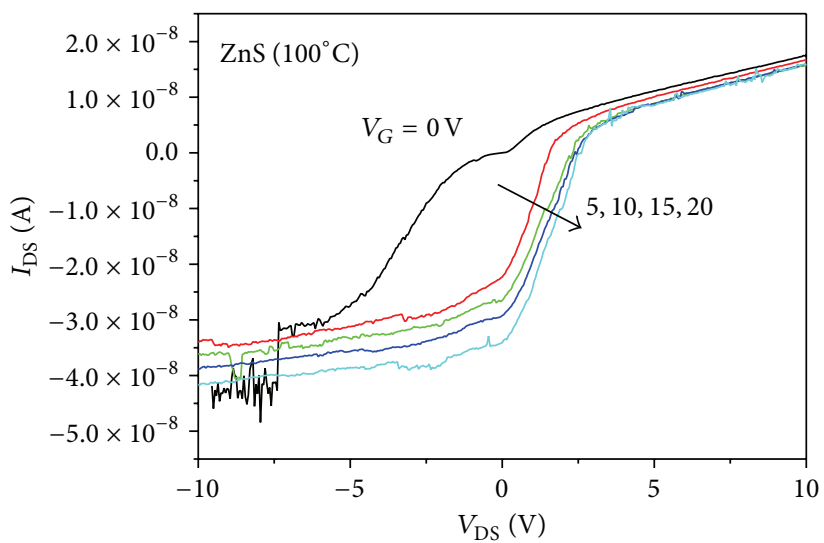

(a)

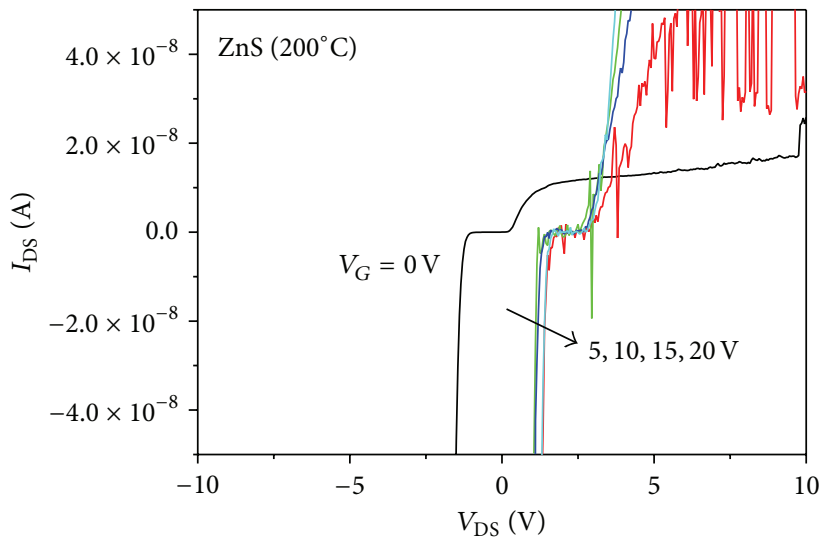

(b)

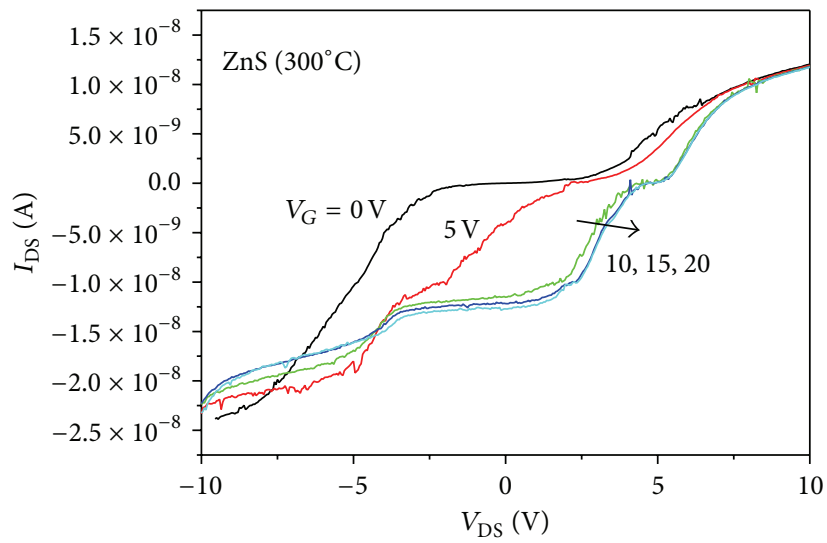

(c)

FIGURE 7: $I_{\text {DS }}-V_{\text {DS }}$ curves of ZnS TFTs annealed at (a) $100^{\circ} \mathrm{C}$, (b) $200^{\circ} \mathrm{C}$, and (c) $300^{\circ} \mathrm{C}$.

\section{Conclusions}

This research included the electrical properties depending on the contact mechanism of $\mathrm{ZnS} / \mathrm{SiOC}$ TFT devices. The electrical characteristics of $\mathrm{ZnS} / \mathrm{SiOC}$ depended on the annealing temperatures. The transfer characteristics of $\mathrm{ZnS} / \mathrm{SiOC}$ TFT were shown as the ambipolar properties with respect to high Schottky barrier, which was made from the reduction of polarities in SiOCs as a gate insulator. The structural matching between $\mathrm{ZnS}$ and SiOC increased the height of SB for a band to band tunneling phenomenon and improved the performance of TFTs. The induction of a depletion layer also caused the decrement of leakage currents by the increment of $\mathrm{SB}$, which was made from the diffusion current fabricated by an electron hole combination due to the difference between carrier concentrations. The diffusion current in a depletion layer and drift current in a channel are two kinds of conduction mechanism in semiconductor devices. The diffusion 


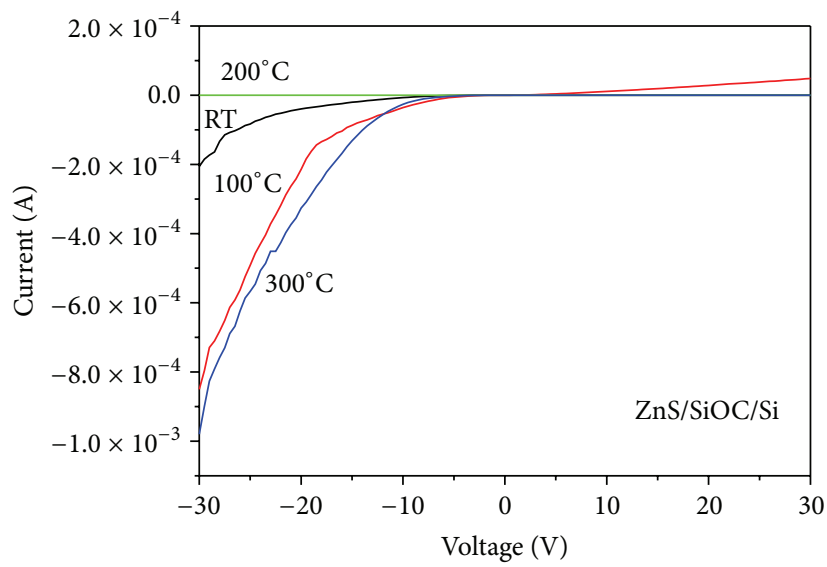

(a)

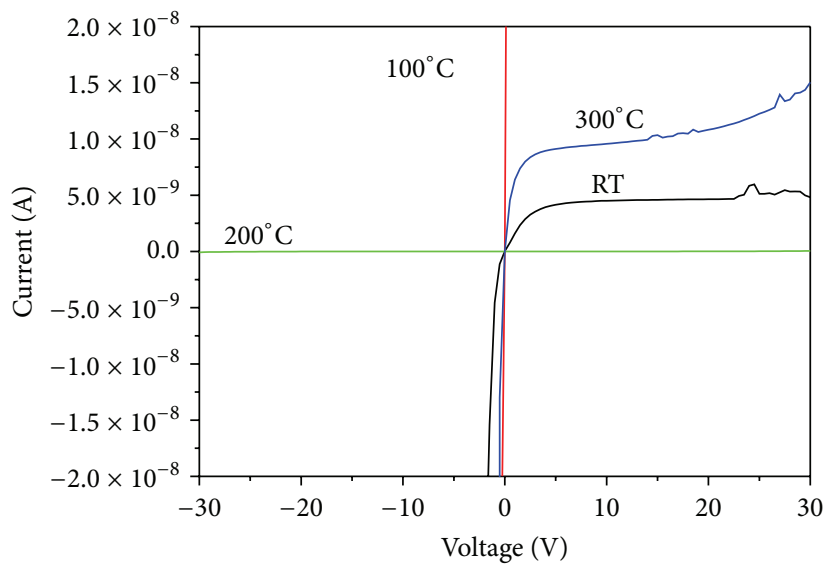

(b)

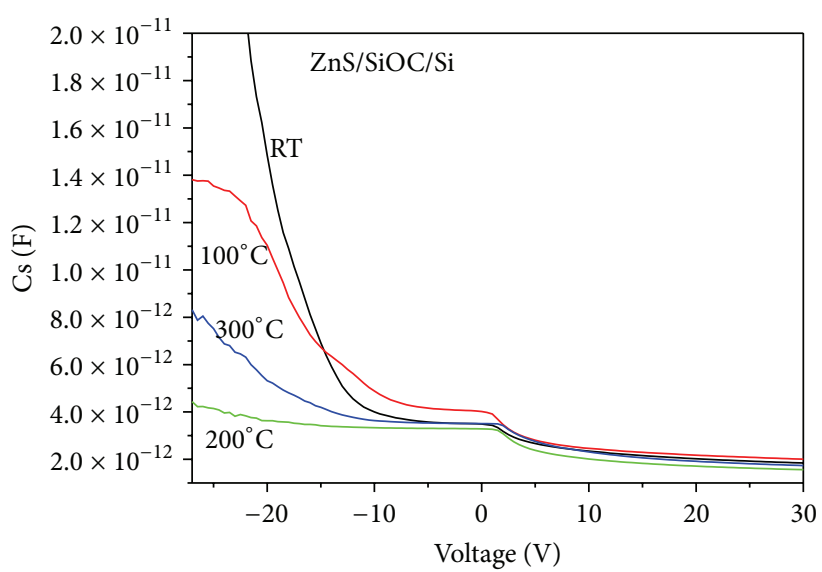

(c)

FIGURE 8: Electrical properties of structure with $\mathrm{Al} / \mathrm{ZnS} / \mathrm{SiOC} / \mathrm{Si}$ substrates to research a contact mechanism, (a) current of $\sim-10^{-4} \mathrm{~A}<I<$ $\sim+10^{-4} \mathrm{~A},(\mathrm{~b}) \sim-10^{-8} \mathrm{~A}<I<\sim+10^{-8} \mathrm{~A}$, and (c) capacitance.

current for a band to band tunneling was proportional to the height of SB, and the leakage current decreased with increasing the SB. Finally, the electrical performance of devices was improved.

\section{Conflict of Interests}

The author declares that there is no conflict of interests regarding the publication of this paper. 


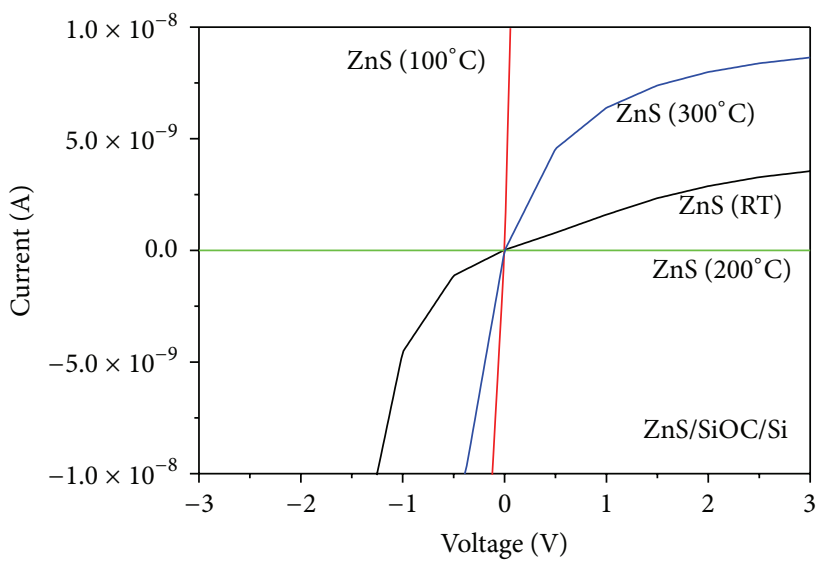

(a)

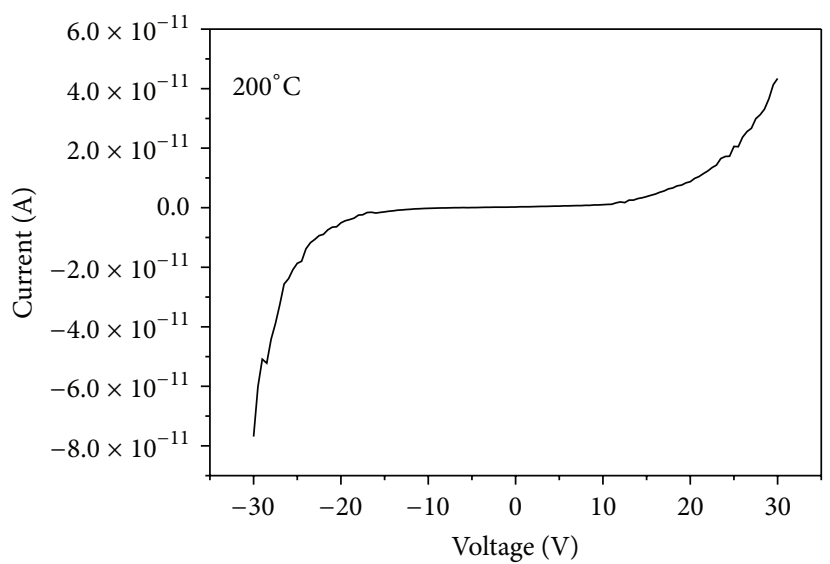

(b)

FIgURE 9: Current-voltage of $\mathrm{Al} / \mathrm{ZnS} / \mathrm{SiOC} / \mathrm{Si}$ structure, (a) Ohmic contact and (b) Schottky contact of sample annealed at $200^{\circ} \mathrm{C}$ in the region of $\sim-10^{-8} \mathrm{~A}<I<\sim+10^{-8} \mathrm{~A}$.

\section{References}

[1] J. Tao, J. W. Chai, Z. Zhang, J. S. Pan, and S. J. Wang, "The energy-band alignment at molybdenum disulphide and highk dielectrics interfaces," Applied Physics Letters, vol. 104, no. 23, 2014.

[2] J. Mu and Y. Zhang, "ZnS thin film prepared through a selfassembled thin film precursor route," Applied Surface Science, vol. 252, no. 22, pp. 7826-7829, 2006.

[3] J. K. Jeong, S. Yang, D. Cho, S. K. Park, C. Hwang, and K. I. Cho, "Impact of device configuration on the temperature instability of Al-Zn-Sn-O thin film transistors," Applied Physics Letters, vol. 95 , no. 12, 2009.

[4] W.-T. Chen, S.-Y. Lo, S.-C. Kao et al., "Oxygen-dependent instability and annealing/passivation effects in amorphous InGa-Zn-O thin-film transistors," IEEE Electron Device Letters, vol. 32, no. 11, pp. 1552-1554, 2011.

[5] L. J. Brillson and Y. Lu, "ZnO Schottky barriers and Ohmic contacts," Journal of Applied Physics, vol. 109, no. 12, Article ID 121301, 2011.

[6] M. E. Lopes, H. L. Gomes, M. C. R. Medeiros et al., "Gate-bias stress in amorphous oxide semiconductors thin-film transistors," Applied Physics Letters, vol. 95, no. 6, Article ID 063502, 2009.
[7] W.-T. Chen, S.-Y. Lo, S.-C. Kao et al., "Oxygen-dependent instability and annealing/passivation effects in amorphous InGa-Zn-O thin-film transistors," IEEE Electron Device Letters, vol. 32, no. 11, pp. 1552-1554, 2011.

[8] J. S. Park, W.-J. Maeng, H.-S. Kim, and J.-S. Park, "Review of recent developments in amorphous oxide semiconductor thinfilm transistor devices," Thin Solid Films, vol. 520, no. 6, pp. 1679-1693, 2012.

[9] T. Oh, "Effects of Schottky barrier in low-k SiOC," Transactions of the Materials Research Society of Japan, vol. 39, no. 4, pp. 475480, 2014.

[10] O. H. Teresa and C. K. Choi, "Comparison between SiOC thin films fabricated by using plasma enhance chemical vapor deposition and $\mathrm{SiO}_{2}$ thin films by using fourier transform infrared spectroscopy," Journal of the Korean Physical Society, vol. 56, no. 4, pp. 1150-1155, 2010.

[11] M. Nakano, T. Makino, A. Tsukazaki et al., "Transparent polymer Schottky contact for a high performance visible-blind ultraviolet photodiode based on ZnO," Applied Physics Letters, vol. 93, no. 12, Article ID 123309, 2008. 
[12] S. D. Ganichev, E. Ziemann, W. Prettl, I. N. Yassievich, A. A. Istratov, and E. R. Weber, "Distinction between the PooleFrenkel and tunneling models of electric-field-stimulated carrier emission from deep levels in semiconductors," Physical Review B, vol. 61, no. 15, pp. 10361-10365, 2000.

[13] O. Mitrofanov and M. Manfra, "Poole-Frenkel electron emission from the traps in AlGaN/GaN transistors," Journal of Applied Physics, vol. 95, no. 11, pp. 6414-6419, 2004.

[14] A. Suresh and J. F. Muth, "Bias stress stability of indium gallium zinc oxide channel based transparent thin film transistors," Applied Physics Letters, vol. 92, no. 3, Article ID 033502, 2008.

[15] K. Nomura, T. Kamiya, and H. Hosono, "Ambipolar oxide thinfilm transistor," Advanced Materials, vol. 23, no. 30, pp. 34313434, 2011.

[16] A. Janotti and C. G. van de Walle, "New insights into the role of native point defects in ZnO," Journal of Crystal Growth, vol. 287, no. 1, pp. 58-65, 2006.

[17] T. Oh, "Correlation between oxygen related bonds and defects formation in $\mathrm{ZnO}$ thin films by using $\mathrm{X}$-ray diffraction and $\mathrm{X}$ ray photoelectron spectroscopy," Korean Journal of Materials Research, vol. 23, no. 10, pp. 580-585, 2013.

[18] T. Oh, "Depletion effect of oxide semiconductor analyzed by hall effects," Journal of Nanoscience and Nanotechnology, vol. 14, no. 12, pp. 9047-9050, 2014.

[19] E. Gili, M. Caironi, and H. Sirringhaus, "Organic integrated complementary inverters with ink-jet printed source/drain electrodes and sub-micron channels," Applied Physics Letters, vol. 100, no. 12, Article ID 123303, 2012.

[20] R. I. Revilla, X.-J. Li, Y.-L. Yang, and C. Wang, "Large electric field-enhanced-hardness effect in $\mathrm{SiO}_{2}$ film," Scientific Reports, vol. 4, article 4523, 2014.

[21] J. Maserjian and N. Zamani, "Behavior of the $\mathrm{Si} / \mathrm{SiO}_{2}$ interface observed by Fowler Nordheim tunneling," Journal of Applied Physics, vol. 53, no. 1, pp. 559-567, 1982.

[22] J. C. K. Lam, M. Y. M. Huang, T. Hau Ng et al., "Evidence of ultra-low-k dielectric material degradation and nanostructure alteration of the $\mathrm{Cu}$ /ultra-low- $\mathrm{k}$ interconnects in timedependent dielectric breakdown failure," Applied Physics Letters, vol. 102, no. 2, Article ID 022908, 2013.

[23] J. Maserjian, “Tunneling in thin MOS structures," Journal of Vacuum Science \& Technology, vol. 11, no. 6, pp. 996-1003, 1974.

[24] J. Frenkel, "On pre-breakdown phenomena in insulators and electronic semi-conductors," Physical Review, vol. 54, no. 8, pp. 647-648, 1938.

[25] G. Venugopal and S.-J. Kim, “Temperature dependent transfer characteristics of graphene field effect transistors fabricated using photolithography," Current Applied Physics, vol. 11, no. 3, pp. S381-S384, 2011.

[26] J. G. Simmons, "Poole-Frenkel effect and Schottky effect in metal-insulator-metal systems," Physical Review, vol. 155, no. 3, pp. 657-660, 1967.

[27] M. J. Kellicutt, I. S. Suzuki, C. R. Burr, M. Suzuki, M. Ohashi, and M. S. Whittingham, "Variable-range-hopping conduction and the Poole-Frenkel effect in a copper polyaniline vermiculite intercalation compound," Physical Review B, vol. 47, no. 20, pp. 13664-13673, 1993.
[28] T. Oh and C. H. Kim, "Correlation between energy gap and defect formation of Al doped zinc oxide on carbon doped silicon oxide," Transactions on Electrical and Electronic Materials, vol. 15, no. 4, pp. 207-212, 2014. 

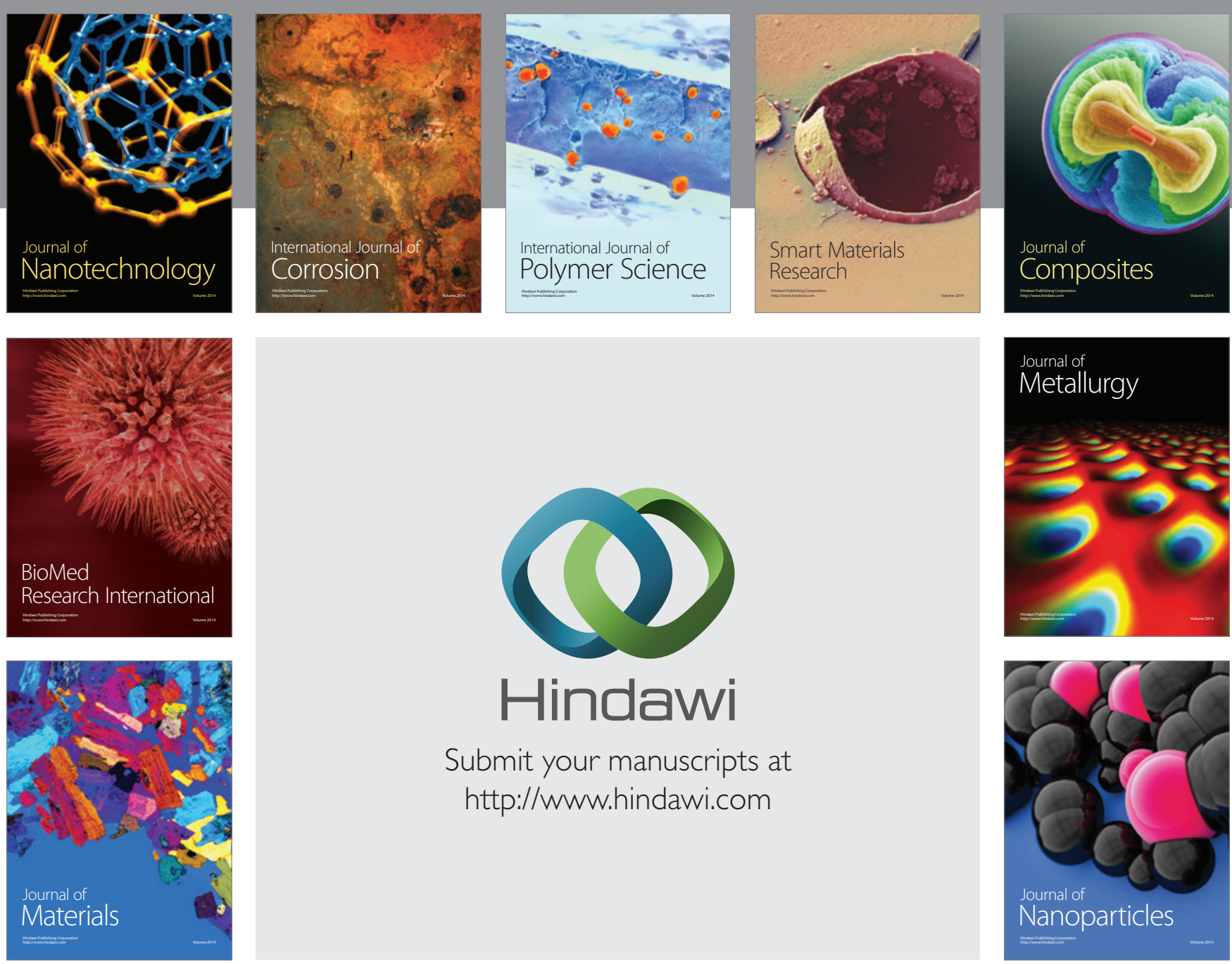

Submit your manuscripts at http://www.hindawi.com
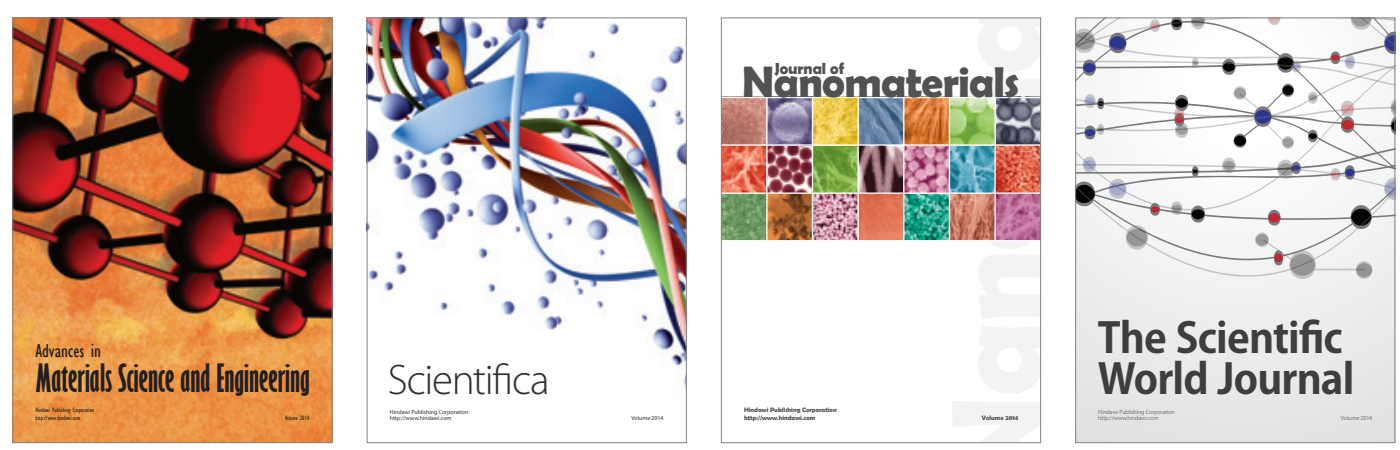

\section{The Scientific World Journal}
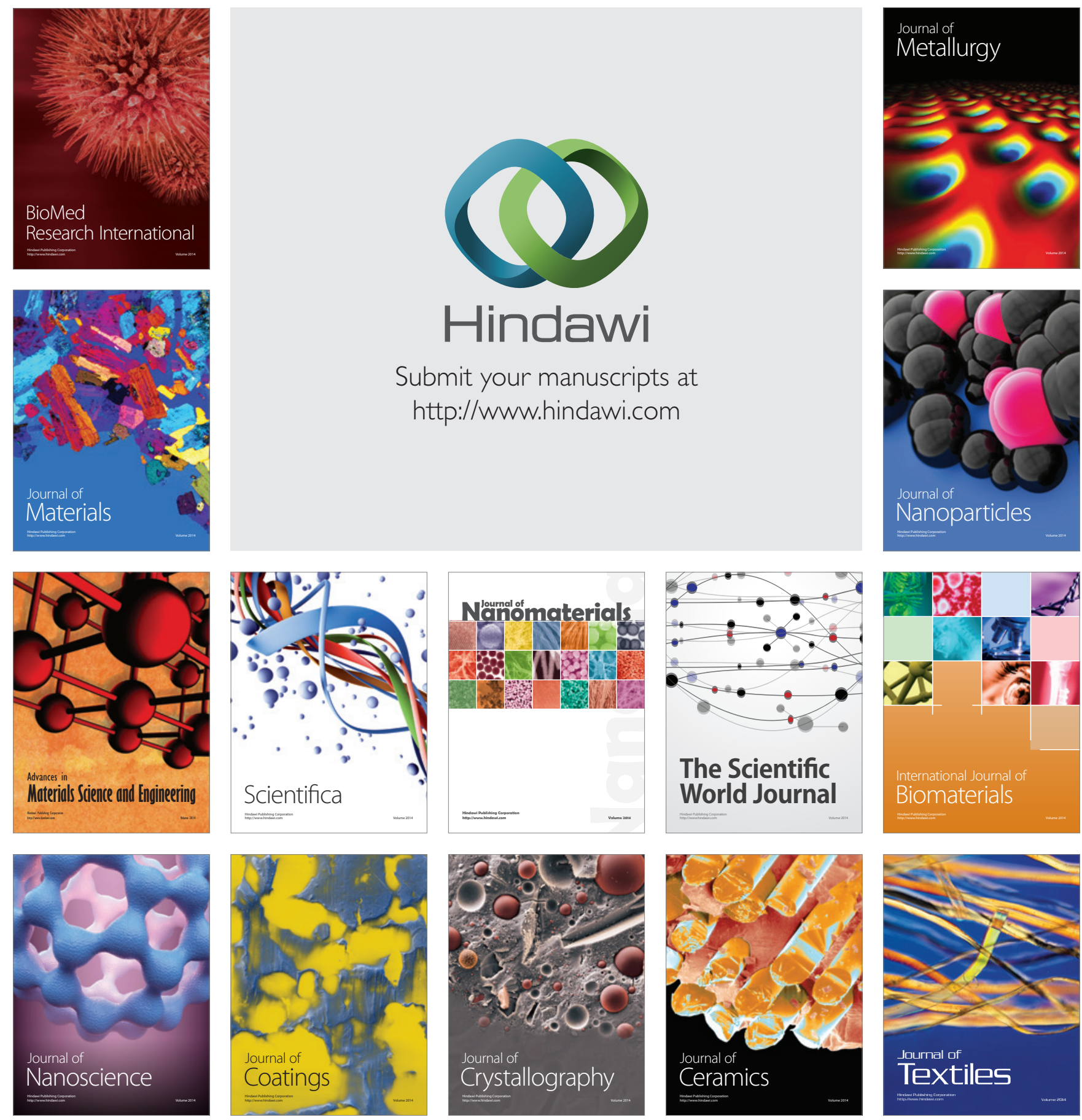